\title{
THE FEATURES OF CONSUMER RIGHTS VIOLATIONS IN ONLINE TRADING
}

\author{
Zaur Azer oglu Mammadli \\ Volgograd State University, Volgograd, Russian Federation
}

\begin{abstract}
Introduction: the development of the Internet and e-commerce has largely changed the habits, behaviors, and preferences of consumers. This dynamic and efficient means of providing goods has been able to overcome many of the obstacles inherent in offline trading. This became especially relevant in 2020 and does not lose its relevance at the present time in the situation of the lockdown precedent on a global scale. It is possible to increase the protection of business entities and, first of all, consumers, if there is an effective system of the legal regulation of the sphere under consideration. There is a need for legally established guarantees, an appropriate level of legal regulation, effective measures, methods and means implemented within the framework of monitoring the compliance with the norms of the current legislation. To protect the rights of consumers, respect their legitimate interests, and create a civilized competitive environment, the state must fully establish legal means to ensure the rule of law in the field of online commerce without restricting the freedoms of entrepreneurs. The purpose of the paper is to review the current state of the violations of the rights of participants in economic relations that occur when making online purchases. Methods: in the process of writing the paper, general scientific methods (qualitative and logical analysis, synthesis, induction, deduction, comparison, system approach, retrospective analysis, morphological analysis), and a special method (scenario analysis) were used. Results: the main aspects related to the legal regulation of electronic commercial activity regarding the protection of buyers are considered. It is indicated that when buying through e-commerce, various violations of consumer rights often occur. This is expressed, in many cases, in the discrepancy between the actual condition of the goods provided to the buyer with the information contained on the seller's website, in the delivery of goods with obvious defects, non-compliance with the requirements of GOST. Conclusions: the protection of the rights of online buyers includes two main aspects. First, it concerns the protection of consumer rights regarding the improper quality of the delivered goods, the specifics of the purchase return, and the funds spent. Secondly, what the world community pays considerable attention to is the legal regulation and protection of consumer data privacy. It is noted that domestic researchers place more emphasis on the first aspect of the problem. It is indicated that the improvement of the legal regulation of e-commerce should be carried out following the global trends in the development of international law in this area.
\end{abstract}

Key words: Internet trading, e-commerce, consumer, product, consumer protection, the legislation of the Russian Federation, electronic transactions.

Citation. Mammadli Z.A. oglu. The Features of Consumer Rights Violations in Online Trading. Legal Concept $=$ Pravovaya paradigma, 2021, vol. 20, no. 3, pp. 149-154. (in Russian). DOI: https://doi.org/10.15688/lc.jvolsu.2021.3.22

УДК 347.451 .031

Дата поступления статьи: 18.04.2021

ББК 67.404 .9 Дата принятия статьи: 05.06.2021

\section{ОСОБЕННОСТИ НАРУШЕНИЯ ПРАВ ПОТРЕБИТЕЛЕЙ ПРИ ИНТЕРНЕТ-ТОРГОВЛЕ}

\author{
Заур Азер оглы Мамедли \\ Волгоградский государственный университет, г. Волгоград, Российская Федерация
}

Введение: развитие Интернета и электронной коммерции в значительной степени изменило привычки, поведение и предпочтения потребителей. Это динамичное и эффективное средство предоставления товаров смогло преодолеть многие препятствия, присущие офлайн-торговле. Особенно актуальным это стало в 2020 г. 
и не утрачивает своей актуальности в настоящее время в ситуации прецедента локдауна в мировом масштабе. Повысить защищенность субъектов предпринимательской деятельности и в первую очередь потребителей представляется возможным при наличии эффективной системы правового регулирования рассматриваемой сферы. Необходимы законодательно закрепленные гарантии, соответствующий уровень правовой регламентации, эффективные меры, способы и средства, реализуемые в рамках осуществления надзора за соблюдением норм действующего законодательства. Для защиты прав потребителей, соблюдения их законных интересов, формирования цивилизованной конкурентной среды государством без ограничений свобод предпринимателей должны быть установлены в полном объеме правовые средства обеспечения законности в сфере онлайновой торговли. Цель: обзор современного состояния отмечающихся нарушений прав участников экономических отношений, возникающих при совершении онлайн-покупок. Методы: в процессе написания статьи применялись общенаучные (качественно-логический анализ, синтез, индукция, дедукция, сравнение, системный подход, ретроспективный анализ, морфологический анализ), специальный метод (сценарный анализ). Результаты: рассмотрены основные аспекты, связанные с правовым регулированием электронной коммерческой деятельности относительно защиты покупателей. Указывается, что при покупке посредством электронной торговли зачастую происходят различные нарушения прав потребителей. Во многих случаях это выражается в расхождении фактического состояния предоставляемых товаров покупателю с той информацией, которая содержалась на сайте продавца, при доставке товара обнаруживаются очевидные признаки брака, несоответствие ГОСТу. Выводы: защита прав онлайновых покупателей включает два основных аспекта. Во-первых, это касается защиты прав потребителей относительно ненадлежащего качества доставленного товара, особенностей возврата приобретенной покупки и затраченных средств. Во-вторых, на что в мировом сообществе обращается значительное внимание, это правовое регулирование и защита конфиденциальности данных потребителей. Отмечается, что отечественными исследователями делается больший акцент на первом аспекте проблематики. Указывается, что совершенствование правового регулирования электронной коммерции необходимо осуществлять в соответствии с мировыми тенденциями в развитии международного права в рассматриваемой сфере.

Ключевые слова: интернет-торговля, электронная коммерция, потребитель, товар, защита прав потребителей, законодательство Российской Федерации, электронные трансакции.

Цитирование. Мамедли 3. А. оглы. Особенности нарушения прав потребителей при интернет-торговле //Legal Concept=Правовая парадигма. -2021. - T. 20, №3.-C. 149-154.-DOI: https://doi.org/10.15688/lc.jvolsu.2021.3.22

\section{Введение}

В современной России сформировано правовое государство с рыночной экономикой. Активно развивается информационное общество и аспекты его правового регулирования. Происходит реформирование многих составляющих, предназначенных для обеспечения динамичного социально-экономического развития страны. Вследствие формирования в Российской Федерации рыночной экономической модели происходит активное развитие предпринимательского сектора. Это подразумевает использование принципов честной конкуренции, свободы перемещения товаров и услуг. Важным условием для эффективности отмеченных процессов является наличие отлаженного механизма правовой защиты участников данного сегмента общественно-экономических отношений [4, с. 43].

Цель статьи заключается в аналитическом обзоре проблем, касающихся нарушения прав участников общественно-экономических отношений, возникающих в процессе электронной (дистанционной, онлайновой) торговли.

Трудно переоценить значение в повседневном бизнесе электронной коммерции - она становится предпочтительным методом заключения сделок различного масштаба, особенно в розничной торговле [3, с. 136]. Во многом это связано со значительными преимуществами, которые онлайновые платформы предоставляют обеим сторонам, главным из которых является удобство, сокращение штата сотрудников, снижение расходов на аренду помещения, относительно высокий уровень обеспечения безопасности осуществляемых сделок, повышение эффективности процессов обмена информацией, рентабельности, ускорение связи с потребителями.

Развитие Интернета и электронной коммерции в значительной степени изменило привычки, поведение и предпочтения потребителей. Это динамичное и эффективное средство предоставления товаров смогло преодолеть многие препятствия, присущие офлайн- 
торговле. Особенно распространенным это стало в 2020 г. и не утрачивает своей актуальности в настоящее время в ситуации прецедента локдауна в мировом масштабе.

Повысить защищенность субъектов предпринимательской деятельности и в первую очередь потребителей представляется возможным при наличии эффективной системы правового регулирования рассматриваемой сферы. Необходимы законодательно закрепленные гарантии, соответствующий уровень правовой регламентации, эффективные меры, способы и средства, реализуемые в рамках осуществления надзора за соблюдением норм действующего законодательства. Для защиты прав потребителей, соблюдения их законных интересов, формирования цивилизованной конкурентной среды государством без ограничений свобод предпринимателей должны быть установлены в полном объеме правовые средства обеспечения законности в сфере онлайновой торговли.

Необходимо урегулировать вопросы, связанные с защитой прав потребителей в рассматриваемой сфере, такие как достаточное и достоверное раскрытие продавцами соответствующей информации, искоренение недобросовестной практики продаж и отказа в возврате товаров, несправедливых условий договоров, недостаточно защищенных методов онлайновых расчетов, повышение уровня защиты личных данных и предоставляемой информации, урегулирование споров правовой защиты и трансграничных онлайновых операций.

\section{Основные проблемы, возникающие при правовом регулировании интернет-торговли}

Очевидно, что онлайн-покупатели сталкиваются со многими неизбежными проблемами, присущими Интернету, особенно в отношении нарушения их потребительских прав. Помимо того, что покупателю может быть предоставлен товар, не соответствующий описанию на сайте компании электронной торговли, в данной форме товарно-денежных отношений присутствует второй аспект, имеющий более важное значение для его урегулирования. Это касается защиты тех сведений, которые потребитель предоставляет продавцу при совершении трансакции. Каждый потребитель имеет право на соблюдение конфиденциальности предоставляемой им информации, на возмещение ущерба в случае его возникновения, на неприкосновенность частной жизни [5, с. 140]. Необходимо более тщательное и продуманное законодательство, регулирующее этот аспект.

Защита личных данных касается безопасности и неприкосновенности информации, предоставленной потребителем в ходе электронной торговли. Прежде чем любая трансакция может быть завершена, потребителю может потребоваться предоставить определенную личную информацию для совершения онлайновой сделки [7, p. 23], что является законным для дистанционной торговли [9, p. 491]. Однако проблема заключается в возможности злоупотребления этой информацией, что может происходить в основном тремя способами:

1. Предоставленная информация может быть использована для целей, не предусмотренных потребителем в то время, когда она была предоставлена (например, маркетинговые операции, интеллектуальный анализ данных).

2. Информация может быть собрана на законных основаниях, но небрежно обработана лицом, владеющим информацией. Распространенные опасения среди онлайновых потребителей - это ненадлежащий уровень безопасности, при котором будут предоставлены их данные. Первостепенное значение имеет и сохранность предоставленной информации.

3. Данные потребителя могут быть использованы в мошеннических целях, информация может быть получена обманным путем, чтобы незаконно снять деньги со счета потребителя либо применить для иных нелегальных целей.

Фактически исследования показали, что эти причины продолжают оставаться основными причинами недоверия потребителей к электронной коммерции как бизнес-модели [2, с. 189]. Так, на международном уровне ОЭСР ввела руководящие принципы по защите прав потребителей в Интернете, выступающие в качестве платформы для странучастниц при разработке собственного национального законодательства в соответствии 
с международным правом. В руководящих принципах подчеркивается, что потребителям, участвующим в электронной торговле, должна быть доступна прозрачная и эффективная защита не ниже уровня защиты, предоставляемой при других форматах процесса торговли. Разработка руководящих принципов Организации Объединенных Наций по защите прав потребителей (UNGCP) является последним важным шагом международного уровня в направлении совершенствования защиты потребителей. UNGCP обеспечивает передовой мировой стандарт для защиты потребителей. Среди региональных механизмов подход Европейского Союза к онлайн-защите потребителей по всему миру имеет большое значение.

\section{Асп екты, касающиеся защиты прав потребителей, осуществляющие онлайновые покупки}

Возникают недостатки и пробелы, многочисленные коллизии при разночтении законодательства, устаревание терминов, упоминания в нормативных документах отмененных ведомств. Также правовая грамотность участников экономических отношений характеризуется недостаточным уровнем.

Состоявшиеся трансформации в общественном развитии, выразившиеся в первую очередь в глобализации и цифровизации пространства, обусловили бурное развитие предпринимательской сферы, осуществляемой в Интернете. Это выражается в заключении дистанционных договоров купли-продажи товаров. Дистанционная реализация продукции осуществляется на территории Российской Федерации на основе договора розничной купли-продажи в соответствии со ст. 497 ГК РФ. Покупатель заключает данный договор в результате процесса ознакомления с описанием товаров, предоставленных продавцом, преимущественно на сайте продавца. Потребитель имеет право осуществить отказ от приобретенного товара в любое время до его передачи, а после передачи товара - в течение 7 дней либо в течение 3 месяцев в случае, если продавец не проинформировал покупателя в письменной форме при доставке товара о порядке и сроках его возврата [1].
В рыночной среде, насыщенной динамичным взаимодействием ее участников, происходит частое нарушение требований норм законодательства в области интернет-торговли. Подобные нарушения выражаются, например, в распространении недостоверных сведений о товарах. Это приводит к нарушению прав и законных интересов в первую очередь потребителей. Существующее российское законодательство в данной области характеризуется пробельностью. Стремительное развитие Интернета нуждается в своевременном адаптированном изменении законодательства. Вероятно, даже может состояться в скором времени выделение данного сектора в отдельную, новую отрасль права, предназначенную для регулирования взаимоотношений, возникающих в Интернете, определение правового статуса субъектов и объектов деятельности, определение видов ответственности за правонарушения в области интернет-торговли.

\section{Рост электронной торговли приводит к возрастанию числа нарушений прав потребителей}

Согласно последним имеющимся оценкам, опубликованным органом ООН по торговле и развитию, ЮНКТАД, объем продаж электронной торговли во всем мире в 2018 г. составил 25,6 трлн долл., что на $8 \%$ больше, чем в 2017 году. Стоимость глобальной электронной коммерции в сегменте В2В в 2018 г. составила 21 трлн долл., что составляет $83 \%$ всей электронной коммерции, включая продажи на платформах онлайн-рынка и транзакции электронного обмена данными. Электронная коммерция В2С была оценена в 4,4 трлн долл., что на $16 \%$ больше, чем в 2017 году. Объем продаж международной В2С-торговли в 2018 г. составил 404 млрд долл., что на 7 \% больше, чем в 2017 году. В 2018 г. более 1,4 млрд чел. сделали покупки в Интернете [8]. В 2019 г. около 1,92 млрд человек приобрели товары или услуги в Интернете, а мировой объем продаж электронной розничной торговли превысил 3,5 трлн долл. США, и ожидается, что рост электронной коммерции в будущем ускорится еще больше.

При совершении онлайновых покупок велика вероятность того, что потребитель 
приобретет товар ненадлежащего качества, то есть будет введен в заблуждение ложной информацией. В ст. 26.1. Закона РФ «О защите прав потребителей» от 07.02.1992 № 2300-1 (ред. от 08.12.2020) обозначены требования к предоставлению потребителям достоверных и исчерпывающих сведений о товарах (их свойствах, местонахождении производителя, полном наименовании, условиях приобретения возврата, сроках и способах оплаты и доставки, гарантийном сроке. В большинстве случаев у потребителя отсутствует возможность произвести визуальный осмотр товара до момента его получения.

Потребителя следует рассматривать как уязвимое звено, так как он приобретает товар, в значительной степени рассчитывая на порядочность продавца. Исходя из сложившейся ситуации и необходимости урегулирования данной сферы отношений, Правительством Российской Федерации было издано распоряжение от 28.08.2017 № 1837-р «Об утверждении Стратегии государственной политики РФ в области защиты прав потребителей на период до 2030 года» [6], в котором приведены цели, достижение которых сможет обеспечить достаточный уровень защиты всех базовых потребительских прав граждан.

\section{Выводы}

Даже при всех преимуществах интернетторговли, ставшей особенно актуальной в ситуации новых вызовов 2020 г., выразившихся во введении карантинных мер, доверие значительной части населения к онлайновой торговле остается низким. Тем не менее цифровизация общества будет возрастать и доля онлайновых приобретений различных товаров неизбежно увеличится. Требуется разработка надежных юридических рычагов, позволяющих регулировать данную сферу экономических отношений с учетом всего их разнообразия. Следует констатировать, что необходимо совершенствование отечественного законодательства, регулирующего деятельность в Интернете с учетом возникновения новых механизмов и инструментов реализации товаров. Требуется более четко обозначить условия, при которых распространение товаров осуществляется на законных основа- ниях, разграничить ответственность всех сторон торговых отношений.

Необходимо приведение нормативных документов в соответствие с современными нормами международного законодательства, упорядочить имеющиеся законодательные акты на предмет их соответствия современным понятиям, условиям осуществления торговой деятельности в Интернете. Требуется пересмотр имеющихся законодательных актов в совокупности с целью исключения дублирования информации, использования устаревших понятий во избежание возникновения юридических коллизий.

\section{СПИСОК ЛИТЕРАТУРЫ}

1. Закон Российской Федерации от 07.02.1992 № 2300-1 «О защите прав потребителей» (ред. от 08.12.2020) // Собрание законодательства РФ. 1996. - 15 янв. (№ 3). - Ст. 140.

2. Козинец, Н. В. Особенности правового регулирования трансграничной электронной торговли : дис. ... канд. юрид. наук / Козинец Никита Владимирович. - М., 2016. -210 с.

3. Матыцин, Д. Е. Обеспечение исполнения государственных и муниципальных контрактов: банковские гарантии и цифровые технологии / Д. Е. Матыцин, И. В. Балтутите // Евразийский юридический журнал. - 2020. - № 11 (150). С. 133-136.

4. Матыцин, Д. Е. Опыт судебного правоприменения по корпоративным спорам, связанным с истребованием акций из незаконного чужого владения и цифровые технологии / Д. Е. Матыцин // Законы России: опыт, анализ, практика. - 2020.№ 10. - C. 43-47.

5. Матыцин, Д. Е. Цифровые технологии реализации гражданско-правовых сделок: договор репо на инвестиционные активы рынка ценных бумаг / Д. Е. Матыцин // Право и практика. - 2020. - № 2. С. 136-140.

6. Распоряжение Правительства РФ от 28.08.2017 № 1837-р «Об угверждении Стратегии государственной политики РФ в области защиты прав потребителей на период до 2030 года» // Собрание Законодательства РФ. - 2017. - № 37. - Ст. 5543.

7. Ariyaratna, R. Protection of Consumer Rights on the Internet: Prospects and Challenges for the Sri Lanka Legal System / R. Ariyaratna // OUSL Journal. 2018. - № 13 (2). - P. 5-23.

8. Global E-Commerce Hits \$25.6 Trillion - Latest UNCTAD Estimates. - Electronic text data. - Mode of access: https://unctad.org/pressmaterial/global-e- 
commerce-hits-256-trillion-latest-unctad-estimates (date of access: 06.02.2021). - Title from screen.

9. Peiris, P. M. An Empirical Study of Customer Adoption of E-Commerce A Customer Trust Model to Support the Adoption of E-Commerce Among Small and Medium Size Enterprises in Sri Lanka / P. M. Peiris, D. Kulkarni // International Journal of Business and Information. - 2015.-10 (4). - P. 491-518.

\section{REFERENCES}

1. Zakon Rossiiskoi Federatsii ot 07.02.1992 № 2300-1 «O zashchite prav potrebitelei» (red. ot 08.12.2020) [Law of Russian Federation of 07.02.1992 No. 2300-1 “On Consumer Rights Protection]. Sobranie zakonodatel 'stva Rossiiskoi Federatsii [Collection of Legislation of the Russian Federation], 15.01.1996, no. 3, art. 140 .

2. Kozinets N.V. Osobennosti pravovogo regulirovaniya transgranichnoi elektronnoi torgovli: dis. ... kand. yurid. nauk [Features of Legal Regulation of Cross-border: Cand. jurid. sci. abs. diss.]. Moscow, 2016. 210 p.

3. Matycin D.E., Baltutite I.V. Obespechenie ispolneniya gosudarstvennyh i municipal'nyh kontraktov: bankovskie garantii i cifrovye tekhnologii [Ensuring the Execution of State and Municipal Contracts: Bank Guarantees and Digital Technologies]. Evrazijskij yuridicheskij zhurnal [Eurasian Legal Journal], 2020, no. 11 (150), pp. 133-136.

4. Matycin D.E. Opyt sudebnogo pravoprimeneniya po korporativnym sporam, svyazannym $\mathrm{s}$ istrebovaniem akcij iz nezakonnogo chuzhogo vladeniya i cifrovye tekhnologii [Experience of Judicial
Law Enforcement in Corporate Disputes Related to the Recovery of Shares from Illegal Alien Ownership and Digital Technologies]. Zakony Rossii: opyt, analiz, praktika [Laws of Russia: Experience, Analysis, Practice], 2020, no. 10, pp. 43-47.

5. Matycin D.E. Cifrovye tekhnologii realizacii grazhdansko-pravovyh sdelok: dogovor repo na investicionnye aktivy rynka cennyh bumag [Digital Technologies for the Implementation of Civil Law Transactions: a Repo Agreement for Investment Assets of the Securities Market]. Pravo i praktika [Law and Practice], 2020, no. 2, pp. 136-140.

6. Rasporyazhenie Pravitel'stva RF ot 28.08.2017 № 1837-r «Ob utverzhdenii Strategii gosudarstvennoi politiki RFv oblastizashchity prav potrebitelei na period do 2030 goda» [Order of the Government of the Russian Federation No. 1837-r Dated August 28, 2017 “'On Approval of the Strategy of the State Policy of the Russian Federation in the Field of Consumer Rights Protection for the Period up to 2030"]. Sobranie zakonodatel'stva Rossiiskoi Federatsii [Collection of Legislation of the Russian Federation], 2017, no. 37, art. 5543.

7. Ariyaratna R. Protection of Consumer Rights on the Internet: Prospects and Challenges for the Sri Lanka Legal System. OUSL Journal, 2018, no. 13, pp. 5-23.

8. Global E-Commerce Hits \$25.6 Trillion Latest UNCTAD Estimates. URL: https:/unctad.org/ pressmaterial/global-e-commerce-hits-256-trillionlatest-unctad-estimates (accessed 6 February 2021).

9. Peiris P.M., Kulkarni D. An Empirical Study of Customer Adoption of E-Commerce A Customer Trust Model to Support the Adoption of E-Commerce among Small and Medium Size Enterprises in Sri Lanka. International Journal of Business and Information, 2015, no. 10 (4), pp. 491-518.

\section{Information About the Author}

Zaur Azer oglu Mammadli, Postgraduate Student, Department of Civil and International Private Law (Base Department of the Southern Scientific Centre of the Russian Academy of Sciences), Volgograd State University, Prosp. Universitetsky, 100, 400062 Volgograd, Russian Federation, mamedlizaur@mail.ru, https://orcid.org/0000-0001-9204-1261

\section{Информация об авторе}

Заур Азер оглы Мамедли, аспирант кафедры гражданского права и международного частного права, Волгоградский государственный университет (базовая кафедра ЮНЦ РАН), просп. Университетский, 100, 400062 г. Волгоград, Российская Федерация, mamedlizaur@mail.ru, https://orcid.org/0000-0001-9204-1261 